\title{
Problem Based Learning Instruction Approaches for Students' Intrinsic Motivation Stimulus
}

\author{
Alias Masek \\ Faculty of Technical and Vocational Education, Universiti Tun Hussein Onn Malaysia, Parit Raja, BatuPahat, Johor, Malaysia \\ Email address: \\ aliasmasek@uthm.edu.my
}

To cite this article:

Alias Masek. Problem Based Learning Instruction Approaches for Students' Intrinsic Motivation Stimulus. International Journal of Vocational Education and Training Research. Vol. 1, No. 3, 2015, pp. 42-48. doi: 10.11648/j.ijvetr.20150103.12

\begin{abstract}
A flawed methodology in the design of Problem Based Learning (PBL) instructional procedure often result in students' discomfort in working in a PBL environment. As a result, student interest might difficult to sustain, and their intrinsic motivation in learning through the PBL process will be difficult to determine. This paper proposes a fourteen-step PBL instructional procedure which addresses intrinsic motivation within the students' learning process. This particular case study addressed a course in the first year syllabus of an Electrical Engineering diploma programme. Within this course, this instructional procedure was experimentally tested and compared with Traditional Learning Approaches (TLA). The results indicated that students' intrinsic motivation level for PBL group exceeded the students' intrinsic motivation level in the TLA. Therefore, the fourteen-step PBL design proposed, was effective in increasing students' intrinsic motivation than that of the TLA.
\end{abstract}

Keywords: Problem Based Learning, Engineering Education, Intrinsic Motivation, Instructional Design

\section{Introduction}

A well-accepted premise in Problem Based Learning (PBL) is that a flawed design in methodology commonly leads to students' frustration and lack of motivation in learning [1]. This is usually true for the institutional curriculum, where a module taught through PBL is inserted as a single intervention, i.e. a single course or within particular topics, amongst a syllabus which is taught using Traditional Learning Approaches (TLA). In such situations, the PBL process appear as a "culture shock" to the students is typically not properly initiated into the PBL environment. Flaws in the design and execution of the PBL procedure, which arise out of the educators' lack of training or understanding on the fundamental PBL methodology, further compound the students' disorientation during the PBL experience $[1,2]$. The overall effect is that the students are frustrated and do not manage to sustain their interest in learning through the PBL process, and consequently, the students' intrinsic motivation in learning due to PBL is difficult to determine [1].

In general, motivation is an important variable that determine students' learning [3] and their persistence in learning [4]. In this context of learning, several PBL elements can stimulate students intrinsic motivation such as the proximal and tangible goals of applying knowledge in solving complex problems [2], responsibility for the process and the solution to a problem rests with them [5], the complexity and the authenticity of the problems, the concept of peers' collaborative learning, and the open-ended solutions concept [6]. Therefore, the challenge is that to design PBL with all these intrinsic motivation stimulus.

In addition, previous studies suggest several additional elements can serve to encourage the students' intrinsic motivation. For example, the design and quality of the PBL problem which are critically important to avoid students' frustration [7]. Also, facilitation must be conducted according to the students' intellectual and learning competency levels [8], where a novice students (first year students) must be facilitated with aggressive guidance [7]. Besides faced with a complex task in aligning PBL to a specific purpose, intended learning outcomes, as well as the institution's mission and vision [9], some practical aspects of PBL might be in contradiction with the TLA paradigm, such as changing students' role from passive (in TLA) to be an active learner (in PBL) [10].

The PBL approach, in its fundamental spirit, is intended to be a motivating, challenging and enjoyable learning approach $[11,12]$. Taking this notion for granted has led to complacency on the part of the PBL practitioner, as it might be taken for granted that students' intrinsic motivation and interest will automatically arise within the PBL environment.As such, at the design stage of the PBL set of procedures, the factor of 
student motivation is typically not built in. These results in a negative student experience within the PBL environment, as they are inadequately prepared to face the paradigm shift from being a passive learner in the TLA, compared to being an active learner in the PBL approach.

This paper proposes a specific PBL instructional procedure that addresses the aspects of students' intrinsic motivation in learning. This particular case study tackles a specific course (Electrical Technology), which is a first year subject in an Electrical Engineering diploma programme. Within this course, a fourteen-step PBL instructional procedure was designed and implemented in an experimental study, in comparison to a TLA, in order to evaluate the efficacy of the PBL approach to encourage students' intrinsic motivation.

\section{The Problem Based Learning model}

$\mathrm{PBL}$ is an innovative teaching and learning method that focuses on the process of solving a problem to gain knowledge [13, 14]. During the instructional process, PBL promotes learning through the process of "learning by doing", whilst the teacher assists the process and plays the roles of a facilitator. This learning process is intended to simulate actual professional practices [13].

PBL has been initially successful in medical education, and subsequently there have been many efforts to implement PBL in other educational disciplines in higher education. The PBL model grew rapidly and was widely adapted into institutional curriculum according to requirements and local needs. To date, PBL has been widely used in higher educational institutions; in China [10], Singapore [13], Malaysia, United Kingdom [8], United State [7]; and Netherlands.

Generally, PBL models are categorized into two types: namely pure and hybrid models $[8,9]$. The pure model refers to the model that is according to the McMaster medical school PBL model. The implementation is without any lectures or tutorial sessions. The hybrid PBL model is in turn, embedded with lectures and tutorial sessions to support students' learning. To date, there is a tendency for universities to adapt the hybrid model in their curriculum. It is due to the nature of PBL approach, which is easy to be adapted into different structures of institutional curriculum. However, without a specific purpose and model reference, the effective implementation of PBL has been difficult to achieve. There is a doubt that curriculum designer might overlook several practical procedures, especially sub-procedures that influence students' performance, such as the quality of the problem, the role of facilitator, and the assessment strategy $[7,13]$.

\section{Methodology}

\subsection{Development of PBL Procedures}

A new structure for PBL procedures was basically developed based on several sources of literature, namely previous research, exemplary models, existing theories, and successful pilot tests that were conducted within Malaysian education context. The procedures for PBL were contained within the three standard PBL practices of [15], namely collaborative, case-centred, and learner-directed instruction. This was to ensure that the instructions were in agreement with the theory and prescriptive procedures. In order to improve the PBL instructions, a framework from [16] was referred to. This framework contained three dimensions that influence cognitive outcomes, namely task dimension, control dimension, and social dimension. Previous research suggests three critical components that form the key success in implementing PBL [17] are namely the quality of problem design, the role of the facilitator, and the assessment strategy $[7,13]$.

Table I. The 14 steps of PBL procedures.

\begin{tabular}{|c|c|}
\hline \multicolumn{2}{|r|}{ STEPS-TASKS (two weeks cycle of problem solving) } \\
\hline \multicolumn{2}{|r|}{ First week (4 hours) } \\
\hline 1. & $\begin{array}{l}\text { Mini lectures- } 10 \text { to } 15 \text { minutes (at any time point) } \\
\text { - Brief on the theory, concepts, principles, and procedures }\end{array}$ \\
\hline 2. & $\begin{array}{l}\text { Group formation (first meeting) } \\
\text { - Lecturer assigns students into a group based on previous test } \\
\text { result } \\
\text { - Four to five members for each group } \\
\text { - Assign and rotate leader for each project } \\
\text { - Retain group for all projects }\end{array}$ \\
\hline 3. & $\begin{array}{l}\text { Problem delivery } \\
\text { - In the form of written scenario } \\
\text { - Tools: problem analysis table, rubrics, grading forms } \\
\text { - Similar set of problem for all groups }\end{array}$ \\
\hline 4. & $\begin{array}{l}\text { Group brainstorming with facilitator } \\
\text { - Identify problem - understand terminology, scenario, } \\
\text { requirements, etc. } \\
\text { - Identify what they know, what they do not know, and what they } \\
\text { need to know } \\
\text { - Formulate learning objectives / learning outcomes } \\
\text { - Assign individual responsibilities and learning objectives } \\
\text { - Facilitator relates the case to real world applications (motivation) } \\
\text { - Facilitator encourages collaboration }\end{array}$ \\
\hline \multicolumn{2}{|c|}{ Outside class (Independent self-study) } \\
\hline 5. & sses discussion and meeting session \\
\hline 6. & Identi \\
\hline 7. & Collec \\
\hline \multicolumn{2}{|r|}{ Second week (4 hours) } \\
\hline 9. & $\begin{array}{l}\text { Reporting progress in a group brainstorming with facilitator } \\
\text { - Report within team } \\
\text { - Prepare for a class information sharing }\end{array}$ \\
\hline 10. & $\begin{array}{l}\text { Short presentation sessions } \\
\text { - Refer to rubric rating scales } \\
\text { - } \text { Peer-assessment } \\
\text { - } \quad \text { Tutor-assessment }\end{array}$ \\
\hline 11. & $\begin{array}{l}\text { Facilitator provides immediate feedback (improvement) } \\
\text { - Based on rubric rating scales } \\
\text { - } \quad \text { Relate learning implication to real-world }\end{array}$ \\
\hline 12. & Groups and facilitator generalize case experience to students' learning \\
\hline 13. & Fills up the fixed reflective questions form \\
\hline 14. & Prepare documentation \\
\hline
\end{tabular}


A variety of key steps and processes were studied and collected from existing pioneering models, such as the Aalborg Model (i.e. project oriented), Maastricht Model (i.e. seven-jump tutorial process), McMaster Model (i.e. self-assessment, independent self-study), and the Republic Polytechnic Model. This combination produced an exemplary PBL instructional procedure that was specifically adapted into an existing engineering education curriculum in polytechnic. The specific procedures were finally presented to several PBL experts for confirmation and validation. This has produced the general fourteen-step-PBL instruction, which is presented in Table I.

\subsection{Instruments}

A questionnaire comprising of 22 items was used to measure students' intrinsic motivation in a pre-test and post-test. The questionnaire contained six subscales, adapted from Intrinsic Motivation Inventory (IMI), namely interest/enjoyment, option/choices, perceived competence, efforts/importance, pressure/tension, and value/usefulness [4]. Students responded to items according to five-points Likert scales to indicate their agreement on the statements. Items were carefully selected from 45 original items in the IMI to maintain the validity of instrument [4]. Items were modified to adapt the general learning context relevant to topics in the two units of Electrical Technology (ET101) module syllabus. For instance, "I put a lot of effort to understand these topics", and "I enjoyed learning in these topics". The Cronbach' Alpha for overall items was 0.77 , which is acceptable above 0.6 [18].

\subsection{Research Design and Sampling}

An experimental pre-test and post-test with control group design was implemented to examine the new structure of PBL by determining the effects of instructions (PBL and TLA) on students' intrinsic motivation. The experiment involved 53 first semester students in two classes, who have enrolled for a Diploma in Electrical Engineering programme in a Malaysian Polytechnic. The course selected to be the test vehicle for the implementation of the designed instructional procedure is the Electrical Technology course, a compulsory course in Electrical Engineering which deals with the fundamentals of circuit theory necessary for the training of any electrical engineer or technologist.

These classes were selected according to two stages of sampling technique (cluster) [19]. In the first stage of sampling, two out of twenty-two polytechnics were selected, which were Polytechnic A $(\mathrm{N}=27)$ and Polytechnic B $(\mathrm{N}=$ 26). In the second stage of sampling, a class (element) in each of these polytechnics was randomly selected according to lecturer, without studying students' characteristics at first place. These classes were randomly assigned to either the experimental (Polytechnic A) or the control group (Polytechnic B). A class in each polytechnic was justified to be homogeneous, since students' entry requirements, intake and placement for polytechnics were standardized and centralized [20]. Also, students were randomly placed in a particular class regardless of their particular characteristics.

\subsection{Treatment Materials}

Five subject-centric problems were developed for $\mathrm{PBL}$ group tasks, which was based on the 3C3R model [7]. The problems were based on the content from two topics within the Electrical Technology (ET101) module syllabus. (Unit 3: An Introduction to Electric Circuit; Unit 4: DC Equivalent Circuit and Network Theorems). These two topics form a very fundamental knowledge for electrical engineers, as it is concerned with the mastery of basic concepts in electrical circuit theory. These topics are concerned with derivation of equations, and are therefore highly dependent on the student's mathematical skills. The learning outcomes of Unit 3 and 4 address generally at Level 1 to 3 of the Bloom's Taxonomy, which is appropriate for a first year course in a Diploma programme. Several subtopics of Unit 3 and 4 were purposely designed to contain repetitive information, in order to enable learning of fundamental knowledge through repetition of particular important concepts, principles, and procedures of Electrical Engineering. The complexity level of the problems ranged from easy to difficult; more hints were provided in the first problem and almost no hints were given for the fifth problem. The contexts of the problems were fictitious but were applicable in real-world situations.

\subsection{Treatment Procedures}

The five PBL problems were used as an instruction material along the 10 weeks of treatment. The timeframe for these units of instruction were fixed into a duration of ten weeks in both groups.

The Control group:In brief, the procedures in the control group were retained as according to the existing setting of TLA. The format for teaching Unit 3 and 4, format was the delivery of a lecture for two hours meeting, followed by an additional two-hour laboratory session later on in the week. In this case, the lecturer was typically active in delivering information and facts, while students acted as passive learners. In certain learning topics, for example the "Kirchhoff's Law", the lecturer had to introduce the theorem before demonstrating the application of the theorem through selected some examples of derivations of equations. Due to the nature of these topics, which contain large amounts of concepts and mathematical principles, the teaching approach using lecturing has always been the primary method of instruction.

The Experimental group:Students were scheduled to solve a problem in two-week blocks to complete one single cycle of PBL procedures. The first week's sessions were generally devoted to groups attending tutorial session and receiving problem scenario. The second week was devoted to assessment activities. The specific problem (subject-centric) was used as a trigger [14] and a short session of lecture (mini-lecture) was used to fill the gaps within the subject-centric problem. The PBL procedures were according to the general fourteen-step-PBL instruction procedures. The 
lecturer was given an instruction manual that provided specific steps of PBL procedure based on the general fourteen-step-PBL.

In the first tutorial session, students were divided into heterogeneous group consisting of four to five members each [14]. A leader was then appointed and rotated for each PBL problem. All groups received the problem in the form of written scenarios. Each group was given several documents, including a problem analysis table, humanistic skills rubric, process skills rubric, and grading forms. A facilitator then conducted a mini lecture to introduce the problem, explain several important concepts, and to explain the students' role. Then, the PBL groups immediately began work to understand the problem.

During problem solving in a tutorial session, the floating facilitator concept was applied. The facilitator moved from one group to another to facilitate students through the process of understanding the problem [13]. Their major tasks were to probe, questions, and monitors group's progress in the tutorial session. In between meeting sessions, students were encouraged to conduct an independent self-study [13] and independent group discussion. Students were also free to collaborate with relevant experts [14].

In the last meeting session, the major activities involved information sharing, assessment, and feedback process [8, 9]. The groups took turns to present their solution proposal. These short presentations were conducted in a group-based format, with all group members presenting their part [14]. During this presentation, other groups performed peer-assessment to evaluate the other groups' performances. At the end of the presentation session, students were asked to rate their team members' performance, according to the rubric rating scale [21]. The facilitator immediately provided feedback to each group $[8,9]$. The facilitator and the students then generalized the learning experience, relevant to the learning outcomes. Finally, one cycle of PBL procedures is ends with students filling in the fixed-reflective question form.

\subsection{Control Factors}

Several variables were held constant to minimize the influence of covariates. For instance, both polytechnics were equivalent and comparable in terms of status and level, days of operation, and staff expertise, the two selected teachers (control and experimental) were equivalent teaching experience and qualification, similar module and topics were used. The teacher in the experimental group was involved in the PBL pilot test and given a special training on PBL.

\section{Findings and Discussion}

There were three students (Experimental group $=2$; Control group $=1$ ) who dropped out from the polytechnic. Only the remaining 50 complete pairs of data that was included in the analysis. Males were dominant, representing $84 \%$ (42) of the respondents. However, gender was equal in both groups. The majority of students (Experimental group $=17$; Control group $=16$ ) were technically grounded from their previous schools, whilst other students were from non-technical streams such as Arts and Sciences.

Data analysis indicated that the mean score of the post-test on the intrinsic motivation questionnaire in experimental group, exceeded the mean score of the control group with $3.987(S D=0.232)$ and $3.820(S D=0.248)$ respectively. Further analysis using the Analysis of Covariance (ANCOVA) indicated that both groups were significantly different $[F(1$, $47)=5.29, p<0.05]$, confirmed that students' intrinsic motivation level for PBL group exceeded the students' intrinsic motivation level in the TLA. The effect size (0.68) was medium with a power of 0.32 [22]. The results of the ANCOVA are presented in Table II.

Table II. ANCOVA for intrinsic motivation scores.

\begin{tabular}{llllll}
\hline Source of variation & d.f. & $\begin{array}{l}\text { Sum of } \\
\text { squares }\end{array}$ & $\begin{array}{l}\text { Mean } \\
\text { square }\end{array}$ & F & $\begin{array}{l}\text { Sig. } \\
\text { level }\end{array}$ \\
\hline Pre-test IM & 1 & .387 & .387 & 7.636 & .008 \\
Group & 1 & .268 & .268 & 5.289 & .026 \\
Error & 47 & 2.381 & .051 & & \\
Total & 50 & 765.071 & & & \\
Corrected Total & 49 & 3.117 & & & \\
\hline
\end{tabular}

$\mathrm{R}$ Square $=.236($ Adjusted R Squared $=.204)$

In the current study, the results indicated that students treated with PBL were intrinsically more motivated than students in their TLA counterparts. Theoretically, the premise that students were intrinsically motivated when their psychological need for autonomy and competence were satisfied, is strongly supported by the findings of this study [23]. From the practical aspect, the PBL instructional procedures were carefully designed and concerned on the aspect of students' intrinsic motivation.

Previous researchers suggested that students may become uncomfortable when PBL is inserted as a single intervention amongst an entire curriculum [1, 2]. Consequently, the students' intrinsic motivation in PBL is difficult to determine [1]. In this study, the course containing the PBL approach was still inserted as a single intervention, but the fourteen-step-PBL instructional procedure was designed in such a way that factors for student motivation was intrinsically embedded within the fourteen-step-PBL instructions.

In terms of delivery and implementation of this PBL instructional procedure, instructor guidance was also imperative. Given the first year level of the students, the facilitator deliberately provided aggressive guidance from table to table, more specific trigger questions were given, and more time was allocated in the tutorial classes. The combination of the right PBL design methodology and proper implementation during the PBL exercises, resulted in an overall increase in the students' intrinsic motivation, despite the fact that this course was also given as a single intervention in the first year curriculum. A right amount of structure in learning environments between controlling elements and students' autonomy [24], provided a theoretical basis in the increase of the students' intrinsic motivation in PBL environment. In short, the right approach to PBL design and 
implementation cushioned the blow of the students' "culture shock" when being placed in a PBL environment, and they adjusted well to their new role as an active learner.

So far, certain elements of the PBL process have been thought to account for the students' intrinsic motivation level, such as problem design and the facilitation process. However in a more systematic approach, four critical components of PBL design were identified, and their contribution to student motivation will be elaborated. The four components are namely: PBL structure, problem orientation, implementation method, and assessment strategy. Each component serves different functions and is interrelated to form a general model of PBL. In fact, the individual function of each component is thought to determine the students' performance and ultimately, the overall success of PBL implementation [7, 13, 16]. In this study, the researcher produces an overview of the PBL instructional procedures, which is depicted in Figure I.

\begin{tabular}{|c|c|c|c|c|c|}
\hline \multicolumn{6}{|c|}{ PBL ELEMENTS } \\
\hline i. PBL structure & \multicolumn{2}{|c|}{ ii. Problem orientation } & \multicolumn{2}{|c|}{ iii. Implementation method } & iv. Assessment strategy \\
\hline $\begin{array}{l}\text { Subject/course-level } \\
\text { Mini lecture } \\
\text { Minimum of two-week } \\
\text { cycle }\end{array}$ & \multicolumn{2}{|c|}{$\begin{array}{l}\text { Multiple formats } \\
\text { Structured } \\
\text { Artificial/real world } \\
\text { Open-ended }\end{array}$} & \multicolumn{2}{|c|}{$\begin{array}{l}\text { Small group } \\
\text { Floating facilitation } \\
\text { Independent study } \\
\text { Independent group } \\
\text { meeting } \\
\text { Seven-jump tutorial } \\
\text { process }\end{array}$} & $\begin{array}{l}\text { Rubric } \\
\text { Individual/group-based } \\
\text { Self-peer-assessment } \\
\text { Facilitator-assessment } \\
\text { Short-presentation } \\
\text { Feedback process } \\
\text { Portfolio documentation } \\
\text { Fixed reflective questions }\end{array}$ \\
\hline \multicolumn{6}{|c|}{ PBL PROCESS CYCLE } \\
\hline \multicolumn{2}{|c|}{ FIRST WEEK } & \multicolumn{2}{|c|}{ GAPS } & \multicolumn{2}{|c|}{ SECOND WEEK } \\
\hline \multicolumn{2}{|c|}{$\begin{array}{l}\text { Mini lecture } \\
\text { Group formation (maintain group) } \\
\text { Distribution of rubric } \\
\text { Problem delivery } \\
\text { Brainstorming the problem } \\
\text { Task distribution \& scheduling }\end{array}$} & \multicolumn{2}{|c|}{$\begin{array}{l}\text { Independent self- } \\
\text { study } \\
\text { Voluntary group } \\
\text { meeting } \\
\text { Unlimited information } \\
\text { resources } \\
\text { Collaboration }\end{array}$} & \multicolumn{2}{|c|}{$\begin{array}{l}\text { Brainstorming-sharing } \\
\text { Short presentation session } \\
\text { Feedback process } \\
\text { Generalisation } \\
\text { Reflection } \\
\text { Documentation }\end{array}$} \\
\hline
\end{tabular}

Figure I. PBL instructional procedures. The top half shows the PBL elements; indicating the compulsory components in the PBL design. The bottom half of the table indicates the PBL process cycle, which is the application of PBL elements, indicating specific procedures of PBL in a two-week block.

The top half of Figure 1 shows the PBL elements; indicating the compulsory components to be included in the PBL design. The bottom half of the table indicates the PBL process cycle, which is the application of PBL elements, indicating specific procedures of PBL in a two-week block. In the context of this research, the PBL design focuses on tuning these elements with the objective of ensuring students' persistence and intrinsically motivated in learning.

Firstly, the PBL structure was chosen to be in the minimum two-week cycle, in order for the student to fully acclimatise to the PBL environment, as well as to allow a proper scheduling for problem assignment, independent learning, and assessment; secondly, problem orientation determines the quality of the problem in terms of being accessible to the student; thirdly, the implementation method determines the level of facilitation during the PBL exercise in the classroom; and fourthly, the assessment strategies includes students' involvement in assessment process.

Problem orientation: The problems were posed multiple formats and were designed to be structured from easy to difficult levels. The researcher designed the first problem with more hints in order to make it easier for students to solve the problem and primarily to avoid students' frustration in problem solving. [7] explained that the amount of hints included in the description of problem (calibration parts) determines the problem difficulty level. It was also necessary to include the reflective component for the student in an explicit manner, in order for the student to pause and identify when they experience a loss of direction in learning. In order to stimulate students' intrinsic motivation, the researcher uses a mock-up problem with actual-world context is applied. Give an example problem within the course. Open-ended problems were posed in order to provide students with autonomous learning and control of their own learning 
conditions.

The Implementation method: Students work in small groups, where they are able to interact, and helps each other. Therefore, there is a high level of participation which contributes to interest and enjoyment of the learning process, which leads to motivation [23]. In order to monitor students' progress and sustain their students' motivation, a floating facilitator concept was applied with aggressive guidance during tutorial sessions [7]. In this way, the facilitator was always available to probe, question, and encourage students to utilise their previous knowledge to solve the current problem. Apart from the time spent during tutorial sessions, the facilitator encourages students to conduct self-study and independent group meetings as deemed necessary.

The Assessment strategy: In this design, the objective of the design was to maximise students' involvement in achieving optimum impact of assessment in PBL $[8,9]$. For that reason, the assessment in the PBL process was mainly based on short presentations executed by individual students, peers, and facilitators. The short presentation was implemented through individual group presentations. The group performance was evaluated by the facilitator and other groups, the marks of which are totalled up as each group's overall score. The facilitator was responsible to provide feedback on students' presentations and problem solution proposals. At the end of the presentation session, each individual performs peer-assessment. Based on the results from peer-assessment, the overall group score are adjusted accordingly; students will be fairly awarded withindividual marks, based on individual performance. In this case, a rubric was extensively used as a tool for the overall assessment activities. The short presentation session is concluded with students completing a fixed-reflective question. Students then collect all their own materials to be compiled for future references.

\section{Conclusion}

The PBL process inserted as a single intervention as course in Electrical Technology, amongst the entire first year of undergraduates' traditional curriculum in a Diploma programme for Electrical Engineering. Poorly designed PBL methodology often resulted in students' frustration and lack of motivation in learning. It is important to have a well designed and structured model of PBL instructional procedure to ensure students' persistence in learning. Based on the positive results from the study, this research proposed a set of exemplary practices of the PBL instructional procedures. The researcher has designed the PBL instructional procedures that places great emphasis on developing the students' intrinsic motivation for learning, and one that will hopefully serve them as a valuable trait in lifelong learning. The fourteen-step methodology proposed in this paper is generally applicable to other engineering courses. This fourteen-step PBL instructional procedure is useful for relevant stakeholders; these come into play for the purpose of teaching and learning or for the development of PBL research, especially in the area of engineering education.

\section{References}

[1] Artino, A.R. (2008). A brief analysis of research on problem based learning. Retrieved From http://www.eric.ed.gov/ERICWebPorta 1/record Detail?accno=ED501593

[2] Hmelo-Silver, C. E. (2004). Problem-based learning: What and how do students learn? Educational Psychology Review, 16, 235-266.

[3] Fink, F.K. (1999). The integration of engineering practice into curriculum-25 years of experience with problem based learning. Proceeding of $29^{\text {th }}$ ASEE/IEEE Frontiers in Education Conference. Puerto Rico: American Society of Engineering Education.

[4] Ryan, R.M. (1982). Control and information in the intrapersonal sphere: An extension of cognitive evaluation theory. Journal of Personality Social Psychology, 43, 450-461.

[5] Savery, J.R. (2006). Overview of problem based learning: Definition and distinctions. International Journal of Problem Based Learning, 1(1),9-20.

[6] Pederson, S. (2003). Motivational orientation in a problem based learning environment. Journal of Interactive Learning Research, 14(1), 51-77.

[7] Hung, W. (2009). The 9-step problem design process for problem based learning: Application of the 3C3R model. Educational Research Review, 4, 118-141.

[8] Savin-Baden, M. (2004). Understanding the impact of assessment on student in Problem Based Learning. Industrial in Education and Teaching International, 41, 223-233.

[9] Savin-Baden, M. (2000). Problem-Based Learning in Higher Education: Untold Stories. Buckingham: Open University Press.

[10] Zhang, G. (2002). Using Problem Based Learning and cooperative group learning in teaching instrumental analysis. The China Papers, October 2002, 4-8.

[11] Norman, G.R. \& Schmidt, H.G. (2000). Effectiveness of problem based learning curricula: Theory, practice and paper darts. Medical Education, 34, 721-728.

[12] Ribeiro, L.R.C. (2008). Electrical engineering students evaluate problem-based-learning (PBL).International Journal of Electrical Engineering Education, 45(2), 152-161.

[13] Wee K.N.L. (2004). Jump Start Authentic Problem Based Learning. Singapore: Prentice Hall Pearson Education South Asia Pte. Ltd.

[14] Kolmos, A., Kuru, S., Hansen, H., Eskil, T., Podesta, L., Fink, F., de Graaff, E., Wolf, J.U. \&Soylu, A. (2007). Problem Based Learning: Special Interest Group B5. Retrieved from TREE Teaching and Research in Engineering in Europe: http://www3.unifi.it/ tree/dl/oc/b5.pdf

[15] Koschmann, T. (2001). Dewey's Contribution to a Standard of Problem-Based Learning Practice. Paper presented at the European perspectives on computer-supported collaborative learning: Proceedings of the $1^{\text {st }}$ European Conference on Computer-Supported Collaborative Learning. Netherland: Maastricht University 
[16] Arts, J.A.R., Gijselaers, W.H. \&Segers, M.S.R. (2002). Cognitive effects of an authentic computer- supported, problem based learning environment. Instructional Science, 30, 465-495.

[17] Masek, A. \&Yamin, S. (2010). Problem Based Learning model: A collection from the literature. Asian Social Science, $6(8), 148-156$

[18] Perera, R., Heneghan, C. \&Badenoch, D. (2008). Statistics toolkit. Massachusetts: Blackwell Publishing.

[19] Black, T.R. (1999). Doing Quantitative Research in the social sciences: An integrated approach to research design, measurement and statistic. London: Sage Publication Ltd.

[20] Department of Polytechnic Education (DPE) (2010).Quick Facts: Transforming lives-April 2010. Retrieved from
Department of Polytechnic Education website: http://politeknik.gov.my/webjpp 2/files/QF_April_2010.pdf

[21] Foldevi, M., Sommansson, G. \&Trell, E. (1994). Problem based medical education in general practice: experience from Linkoping, Sweden. British. Journal of General Practice, 44, 473-476.

[22] Cohen, J. (1992). A power primer. Psycho. Bull., 112,155-159.

[23] Ryan, R.M. \&Deci, E.L. (2000). Self-Determination Theory and the facilitation of intrinsic motivation, social development, and well-being. American Psychologist, 55(1), 68-78.

[24] Wijnia, L., Loyens, M.M.S. \&Derous, E. (2011). Investigating the effects of problem-based versus lecture-based learning environments on student motivation. Contemporary Educational Psychology, 36(2), 101-113. 